\title{
Pollution on the upswing
}

\section{Tokyo}

JAPANESE industry has set an example for the world by reducing its energy consumption and carbon dioxide emissions through energy-efficient technology and production processes. But Japan's 120 million citizens and the nation's trucking companies are rapidly undoing all this hard work. According to the latest annual white paper (policy document) on the environment, released last week by the Environment Agency, Japan's consumer and transport sectors are steadily increasing their consumption of energy and emission of pollutants - cancelling out the environmental gains made by Japanese industry.

Although the small and comparatively young Environment Agency has little political clout in the Japanese government, it has become increasingly bold in its pronouncements, reacting to growing concern about the global environment. And its recent white papers have attracted worldwide as well as national attention.

The white paper, in what the agency claims is a first for any country in the world, breaks down carbon dioxide emissions in Japan into four sectors: industry, private households, transport and energy conversion and electric power transmission losses. The breakdown provides a revealing insight into where Japan's carbon dioxide problems lie.

Analysis of emissions over the past 25 years reveals that carbon dioxide discharges from industry fell significantly after the 1973 oil crisis, as industry rallied to improve its energy efficiency. Industry's share of total emissions has accordingly dropped from 60.2 per cent in 1973 to 49.5 per cent in 1989. And this was achieved against a background of a rising gross national product and industrial production (except for a brief period of negative growth immediately after the oil crisis).

On the other hand, consumption of energy and carbon dioxide emissions in private households have continued to rise steadily. Households now account for 23.2 per cent of all emissions, compared with 18 per cent in 1973 , and their share of electricity use has also expanded dramatically as more and more Japanese homes have installed airconditioning units and other electrical appliances.

Similarly, the share of emissions from the transport sector climbed from 13 per cent in 1973 to nearly 20 per cent today. According to the white paper, the biggest culprits are the small- to medium-sized companies that operate the thousands of diesel trucks that now jam Japan's narrow roads. The trucks not only emit carbon dioxide but also contribute much of Japan's nitrogen oxide $\left(\mathrm{NO}_{\mathrm{x}}\right.$ ) pollution.

Paradoxically, Japan has some of the strictest regulations in the world for control of emissions from cars. The regulations were introduced because of severe urban pollution problems in the 1960 s and early 1970 s, and, as a result, $\mathrm{NO}_{x}$ pollution in Japan's cities decreased steadily from a peak in the mid-1970s until the mid-1980s. But the white paper shows that since $1985, \mathrm{NO}_{\mathrm{x}}$ pollution has been on the rise again, and the major source of this pollution is diesel trucks.

Emission controls for diesel engines are not so strict as for gasoline-driven vehicles and, because diesel fuel is considerably cheaper than gasoline, there has been a boom in the use of diesel trucks among small trucking companies, which have expanded their operations dramatically in recent years. The boom in the trucking business has been caused by increased demand for private parcel delivery services and by the general expansion of consumption of products in Japan's increasingly affluent society.

Ten years ago, the millions of small convenience stores and groceries that line the streets of Japanese cities managed with only one or two deliveries by truck per day. But now, as manufacturers compete ferociously to grab a share of the market, dozens of deliveries in a day are not uncommon. One example, cited in television reports last week, is the current 'beer war', where beer manufacturers have flooded the market with 174 marginally different brands of lager beer - all of which need transporting to retail outlets.

The problem is compounded by Japan's grossly inadequate road system. Tokyo has a network of toll-charge 'expressways' built in the $1960 \mathrm{~s}$. But these major arteries are only two lanes wide and at some key junctions they narrow to one lane. Traffic jams that extend for miles are an everyday event. And the jams are getting worse every year as more trucks and cars flood the roads.

Kei Takeuchi, an economist at Tokyo University's Research Center for Advanced Science and Technology, who leads a team of researchers trying to find social and economic solutions to global environment problems, blames the Japanese government for much of the problem. It is all very well for the Japanese automobile industry to offer leading-edge emission controls and fuel-efficient cars, he says, but until the government takes the initiative to solve Tokyo's traffic jams, no amount of technology will ease the city's growing pollution problems.

A few months ago, the Tokyo metropolitan government tried to improve the situation by asking transport companies to refrain from using their vehicles on Wednesdays. But only 5 per cent of 5,500 companies complied.

Toshiro Kojima, director of the planning and research division of the Environment Agency, says the agency hopes that the price differential between diesel and gasoline fuel will be eliminated and tax incentives will be introduced to encourage transport companies to stop using diesel trucks. But because the trucks typically cost about $¥ 10$ million $(\$ 70,000)$ each and last for years, he admits that a rapid switchover is unlikely. David Swinbanks

\section{ENVIRONMENT}

\section{One Westerner gets it RITE in Japan}

Tokyo

LAST week, when the Japanese Research Institute of Innovative Technology for the Earth (RITE) announced the 12 winners of grants for research on the global environment, 11 were Japanese scientists, even though the programme was in theory open to researchers of all nations. The result is not too surprising, however, given the way in which the grants were publicized outside Japan - that is to say, not at all.

The episode illustrates how the Japanese sometimes send conflicting signals to the rest of the world - in this case, seemingly asking for outside participation but discouraging it at the same time.

RITE was established last year by the Ministry of International Trade and Industry (MITI) to develop 'environmentfriendly' technology (see Nature 350, 266; 1991). As part of its task, it offered the 12 grants, which range in value from $¥ 3$ million to $¥ 7$ million $(\$ 22,000-\$ 50,000)$ a year. MITI decided that the institute should open up the programme to nonJapanese as part of a policy to internationalize MITI's research projects.
But unfortunately for non-Japanese scientists, the New Energy and Industrial Technology Development Organization (NEDO) , in conjunction with RITE, is responsible for funding and publicizing the grants. NEDO is a semi-government organization that runs most of MITI's projects, including RITE, and it does not seem to share the ministry's enthusiasm for internationalizing the projects.

For the RITE programme, English literature describing the grants was sent to foreign embassies in Tokyo, but the only other announcements appeared in Japanese publications and were written, of course, in Japanese.

Very few non-Japanese scientists noticed the announcements for the new programme before the deadline in late January, and only one will receive an award. S. C. Jarvis of the UK Agricultural and Food Research Council's Institute of Grassland and Environmental Research will get $¥ 6$ million to study methods to enhance the capacity of agricultural soils to provide sinks for methane.

David Swinbanks 